\title{
A REPRESENTAÇÃO CRIMINAL NOS CRIMES DE LESÃO CORPORAL LEVE, CULPOSA E CONTRAVENÇÕES PENAIS DE VIAS DE FATO; VIOLÊNCIA DOMÉSTICA E FAMILIAR
}

\author{
Luiz Renato Mendonça Zissmann, Eduardo Buzetti Eustachio Bezerro \\ Universidade Do Oeste Paulista, UNOESTE, curso de Direito, Presidente Prudente, SP. E-mail: \\ luizzissmann@hotmail.com
}

\begin{abstract}
RESUMO
A mulher vítima de violência doméstica e familiar é tutelada pelo ordenamento jurídico brasileiro que adotou medidas de rigor com a Lei 11.340/2006 passando a tratar os crimes de lesão corporal leve e culposa e contravenções de vias de fato como de ação penal incondicionada. Logo o objetivo desse estudo consistiu em discutir os limites do Estado em interferir no ambiente doméstico e familiar em situações em que a vítima manifesta em não exercer a representação criminal em desfavor de seu ofensor para preservar o convívio familiar sob a óbice do artigo 226 da Constituição Federal mesmo diante do entendimento turbado e consubstanciado pela jurisprudência. O método empregado foi o dedutivo legal mediante auxílio doutrinário e jurisprudencial, restando concluir que a suprema corte foi infeliz em abordar sobre decisões que merecem tratamento individualizado sub-rogando na oportunidade da incidência da destituição familiar.

Palavras chaves: Violência doméstica e familiar. Lesão corporal leve e culposa. Vias de fato. Ação penal incondicionada. Representação criminal.

THE CRIMINAL REPRESENTATION IN THE CRIMES OF LIGHT BODY INJURY, CRIME AND CRIMINAL CONTROVERSTIONS OF FACTS; DOMESTIC AND FAMILY VIOLENCE
\end{abstract}

\begin{abstract}
Woman who is a victim of domestic and family violence is protected by the Brazilian legal system, which has adopted strict measures with Law 11.340 / 2006, dealing with crimes of light bodily injury and misconduct and contraventions of de facto remedies such as unconditional criminal action. Therefore, the objective of this study was to discuss the limits of the State in interfering in the domestic and family environment in situations where the victim manifests in not exercising criminal representation to the detriment of his offender to preserve family life under the obstacle of Article 226 of the Constitution Federal law, even in the face of the disturbed understanding, embodied in the jurisprudence. The method used was the legal deductive through legal aid and jurisprudential, remaining to conclude that the supreme court was unfortunate to address decisions that deserve individual treatment subrogating the opportunity of the incidence of family destitution.
\end{abstract}

Key words: Domestic and family violence. Light bodily injury. In fact. Unconditional criminal action. Criminal representation

\section{INTRODUÇÃO}

A discriminação do gênero feminino insiste em persistir no ambiente doméstico e familiar da sociedade civilizada, entretanto mesmo nos dias atuais, motivados pela cultura e religião, elevados são os índices que demonstram a presença da repressão dos direitos humanos das mulheres. 
Ocorre que os crimes cometidos contra a mulher dentro do ambiente doméstico e familiar, passou a ser analisado através das convenções e tratados internacionais, a interferência do Estado detentor do jus puniendi ignorar a vontade da vítima em não representar criminalmente o seu ofensor mediante a imposição de medidas de rigor em fatos cujo a mulher figure como vítima em crimes precedidos por decorrência do seu gênero.

Destaca-se que o ordenamento penal brasileiro apresenta em seu artigo 100, §1ㅇ a presença da representação criminal da vítima como requisito imprescindível para que o legitimado para propositura da ação provoque a jurisdição criminal.

Nessa seara, a problemática se consuma diante a observância das medidas de rigor impostas em crimes de violência doméstica contidas no artigo 41, que na oportunidade afasta incidência da Lei 9.099/95, passando os crimes de lesão corporal leve e culposa procederem independente da vontade da vítima restando ao Ministério Público seguindo o princípio da obrigatoriedade, oferece a ação penal por ser publica incondicionada mesmo em situações em que a tutela pertinente seja a promoção da família.

Aprofundando-se no assunto, iremos verificar as condições de procedibilidade nas contravenções de vias de fato, que por si só já é questionável haja vista, a sua natureza incondicional.

Logo, o presente estudo seguirá o método dialético-dedutivo, com emprego de pesquisa à legislação, doutrina e jurisprudência acerca da matéria objeto da investigação, apontando os posicionamentos sobre a condição da ação nos crimes de lesão corporal leve e culposa, e contravenções de vias de fato, diante da possibilidade da vítima exercer o seu direito de renúncia cujo crime proceda-se mediante representação, sabendo que a Lei 11.340 de 2006 suprime a Lei 9.099/95, não se esquecendo de abordar os contextos de atribuição da lei como em dar rigorosidade, e por outro lado o amparo Constitucional da permanência da família como base da sociedade Brasileira.

\section{METODOLOGIA}

O presente estudo seguirá os métodos dialético-dedutivo, com emprego de pesquisa à legislação, doutrina e jurisprudência acerca da matéria objeto da investigação.

\section{RESULTADOS}

O resultado do presente estudo consiste no entendimento favorável do Supremo Tribunal Federal em tratar crimes de lesão corporal e contravenções de vias de fato sendo como de natureza incondicionada, justificando a imposição rigorosa da Lei 11.340/2006 em afastar a Lei 9.099/95 através das circunstâncias dos fatos que se exprimem no depoimento da vítima que renunciou a permanecia do vínculo familiar no momento em que procurou ajuda do Estado.

\section{CONDIÇÕES DA AÇÃO PENAL}

O Estado é detentor do jus puniend, e tem atribuição de utilizar-se de sua pretensão punitiva para aplicar a lei quando provocado, fazendo assim, emergir o direito prevalecendo a justiça.

A ação penal por via de regra é pública, apenas em casos especiais procede-se mediante queixa-crime, entretanto não se limita apenas em casos que dependam da representação da vítima, em algumas situações a ação penal é incondicionada.

Para Prado (2015, p.612): "Sendo a ação penal pública incondicionada, estarão dispensados quaisquer requisitos para a sua promoção. O Ministério Público oferecerá denúncia independentemente de representação da vítima" 
Ocorre que o ordenamento penal brasileiro, oportuniza através do artigo 100, §1 que ação penal pública proceda mediante representação da vítima em casos em que a lei exija.

Explica Paccieli (2017, p.108), que ação penal é a peça cabível para a provocação do poder judiciário diante de uma situação controvertida por decorrência de um ilícito penal, e sendo ela pública, passa o Ministério Público atuar como legitimado na ação ressalvando em alguns casos a necessidade da condição da vítima em dar prosseguimento na ação sob pena na ausência de condição, a extinção da punibilidade do autor.

Para que a identificação da condição ocorra as disposições contidas no artigo do código penal exige a condição da vítima para que o Estado de prosseguimento da ação como é nos casos dos crimes de ameaça, lesão corporal leve ou culposa, estupro desde que a vítima seja maior, etc. (MOUGENOT, 2016, p.247).

Logo, a ação penal consiste na cumulação de requisitos, e quando tratamos sobre a condicionalidade da ação, passamos a analisar requisitos processuais para dar o prosseguimento da ação.

Entretanto, mesmo diante de um fato gerador que exija a condicionalidade da ação, resiste questionar sobre o fundamento legal em oportunizar a vítima em não querer ver a sanção penal imposta sobre o seu ofensor.

Segundo Marcão (2014, p.229): “Nesses casos, procura-se impedir que a investigação e o processo causassem mal ainda maior ao ofendido, daí a lei condicionar a instauração da persecução ao desejo do interessado".

Contribui Capez (2013, p. 175):

Nesse caso, o crime afeta tão profundamente a esfera intima do indivíduo, que a lei, a despeito da sua gravidade, respeita a vontade daquele, evitando, assim, que o strepitus judicii (escândalo do processo), se torne um mal maior para o ofendido do que a impunidade dos responsáveis.

Por tanto, o inquérito policial instaurado para apurar a prática do crime de ameaça depende do termo de representação da vítima em exercer a condição da ação para a futuro oferecimento pelo parquet, pois, não havendo, caberá ao legitimado requerer o arquivamento por ausência de interesse.

Ocorre, como veremos adiante, que os crimes de lesão corporal leve e culposa e as contravenções de vias de fatos procede-se mediante representação da vítima, entretanto com a incidência da Lei 11.340 de 2006, esses crimes passaram a ser de natureza incondicional, afastando a decisão da vítima em relação aos fatos resultando no prosseguimento do processo que pode ser mais prejudicial do que a própria lesão.

\section{A REPRESENTAÇÃO CRIMINAL EM CRIMES DE LESÃO CORPORAL LEVE E CULPOSA E CONTRAVENÇÕES PENAIS DE VIAS DE FATO}

As condições de procedibilidades da ação penal encontradas no artigo $100 \S 1^{\circ}$ do Código Penal e a incidência do artigo 88 da Lei 9.099 de 1995, apresenta a anuência da vítima nos crimes de lesão corporal leve e culposa, logo, surgiu a polêmica da vítima de violência doméstica e no âmbito da unidade familiar, exercer o seu direito de renúncia a representação estipulada no artigo 16, da Lei 11.340 de 2006, tendo em vista que o artigo 41 do mesmo diploma proibi à aplicabilidade da Lei 9.099/95, tornando a ação penal em incondicionada (CUNHA, 2015 p.117).

Ocorre que o artigo 129 do Código Penal dispõe que o crime de lesão corporal em todas as suas generalidades procede-se incondicionalmente e o artigo 88 da Lei 9.099/95 regulamenta que os crimes de lesão corporal leve e culposa se procede mediante representação da vítima, e nesse 
interim a Lei 11.340 de 2006 afasta a incidência da Lei 9.099/95 restando para o Ministério Público oferecer a ação devido as diretrizes do Código Penal.

Logo, com a finalidade de sanar a ação penal em crimes de lesão corporal leve e culposa, no ano de 2012 a Procuradoria Geral da República através da ação declaratória de inconstitucionalidade 4.424, propôs a discussão sobre a legalidade da Lei 11.340 de 2006 restando o informativo 654 do Supremo Tribunal Federal pacificar o assunto manifestando que os crimes de lesão corporal em ambiente doméstico, cuja vítima é mulher, a ação penal é pública e incondicionada ${ }^{1}$ (BIANCHINI, 2016, p.255).

Apesar das controvérsias encontradas nos acórdãos do Superior Tribunal de Justiça antes do advento da ação declaratória de inconstitucionalidade (ADI) 4.424, verifica-se com a edição da súmula 542 a pacificação sobre o tema: "A ação penal relativa ao crime de lesão corporal resultante de violência doméstica contra mulher é pública incondicionada" (NUCCI, 2015, p.792).

Sendo assim, conclui-se que os crimes de lesão corporal praticados no âmbito da violência doméstica ou familiar contra a mulher, afasta a condicionalidade da ação penal tornando-se impossível a mulher retrata-se de sua decisão na audiência especifica para o ato.

Registra-se ainda, a problemática contida na contravenção penal de vias de fato que mesmo diante de uma lesão corporal que nem se quer deixou marcas, o entendimento pacificado pondera pela incondicionalidade da ação.

Curiosos os exemplos apresentados pela doutrina, em que apresenta casos como: corte de barba ou cabelo como hipótese de aplicabilidade de vias de fato afastando o crime de lesão corporal (PRADO, 2015, p.691).

Contribui Nucci (2015, p.114): “Ora, se o mais (lesão corporal) demanda a autorização do ofendido, é óbvio que o menos (vias de fato) também deve exigir representação".

Outrora a dinâmica anteriormente já exaltada, em que fora abordado sobre o condicionamento da ação nos crimes de lesão corporal leve e culposa, o fundamento dado por Nucci (2015, p.114), Damásio (2015, p.90) e Maciel (2010, p.112), consiste em ignorar a incondicionalidade da ação encontrada no artigo 17 da Lei de Contravenções Penais e aplicar o artigo 88 da Lei $9.099 / 95$, por motivos óbvios, é controverso condicionar o mais grave e tratar como incondicional o mais brando, contrariando assim, a decisão do Supremo Tribunal Federal que opinou pela incondicionalidade da ação ponderando pela aplicação do artigo 17 da Lei 3.688/41.

Entretanto, como bem analisado pela doutrina o condicionamento da ação se dá mediante o mesmo fundamento das lesões corporais leve e culposa, ou seja, a aplicabilidade da Lei 9.099/95.

Ocorre que a Lei 11.340/2006 afasta aplicabilidade da Lei 9.099/95 passando as contravenções de vias de fatos ser de natureza incondicionada.

A doutrina vem resistindo sobre esse entendimento, tendo em vista a natureza da lesão, pois, de tão ínfima, não justifica não oportunizar a mulher em decidir sobre a representação criminal de seu ofensor principalmente quando contraia a preservação da família contida no artigo 226 da Constituição Federal.

\footnotetext{
${ }^{1}$ Decisão: O Tribunal, por maioria e nos termos do voto do Relator, julgou procedente a ação direta para, dando interpretação conforme aos arts. 12, inciso l, e 16, ambos da Lei n. 11.340/2006, assentar a natureza incondicionada da ação penal em caso de crime de lesão, pouco importando a extensão desta, praticado contra a mulher no ambiente doméstico, contra o voto do Senhor Ministro Cezar Peluso (Presidente). Falaram, pelo Ministério Público Federal (ADI 4.424), o Dr. Roberto Monteiro Gurgel Santos, Procurador-Geral da República: pela Advocacia-Geral da União, a Dra. Grace Maria Fernandes Mendonça, Secretária-Geral de Contencioso: pelo interessado (ADC 19), Conselho Federal da Ordem dos Advogados do Brasil, o Dr. Ophir Cavalcante Júnior e, pelo interessado (ADI 4.424), Congresso Nacional, o Dr. Alberto Cascais, Advogado-Geral do Senado. Plenário, 09.02.2012. Dispositivos questionados: arts. 12, I, 16 e 41 da Lei Maria da Penha.

Colloquium Socialis, Presidente Prudente, v. 01, n. Especial 2, Jul/Dez, 2017, p.127-132. DOI: 10.5747/cs.2017.v01.nesp2.s0125
} 
Cabe ressaltar que o crime de ameaça, que consiste na iminência de mal injusto e grave, depende da representação da vítima, restando o questionar a fragilidade do entendimento gravoso nas contravenções de vias de fato.

Ora, observa-se que a incidência da Lei 11.340/06 em que proibi a aplicabilidade da Lei 9.099/95, bem como, a influência do artigo 17 do decreto 3.688/41 apresenta o inconformismo lastreado nas dinâmicas comparativas dos fatos em que apesar de ocorrerem no ambiente doméstico, contraditório é o entendimento de agravar uma lesão que nem se quer deixou marcas.

O Superior Tribunal de Justiça após apresentar entendimentos favorável e contra, pacificou após decisão do Supremo Tribunal Federal que as contravenções penais quando cometidas no ambiente doméstico deverá ter o tratamento de ação penal pública incondicionada.

Complementou ainda o Supremo Tribunal Federal fundamentando favoravelmente pela conversão das penas privativas de liberdade em restritivas de direitos, sendo observadas as restrições do artigo 17 da Lei 11.340/2006.

Por tanto vimos que os crimes de lesão corporal leve e culposa e as contravenções de vias de fato procede-se independentemente da representação da vítima por força do artigo 41 da Lei 11.340/06. Logo, a audiência preliminar do artigo 16 é ineficaz tendo em vista a impossibilidade da vítima em renúncia a representação.

Restando concluir, que mesmo diante da contravenção penal, verifica-se que a tutela da Lei 11.340/06 não se justifica na agressão em si, mais sim, em todas as circunstâncias que norteiam os fatos, logo, na ocorrência de vias de fato, presume-se a precedência de variadas formas de violência, como a psicológica, que no presente momento foi exteriorizada com a pratica da contravenção.

\section{CONCLUSÃO}

O presente artigo objetivou elucidar o recente tratamento normativo brasileiro no direito de representação da vítima em crimes de lesão corporal leve e culposa e contravenções penais de vias de fato que ocorreram contra a mulher em seu ambiente doméstico e familiar.

De início fora observado o posicionamento do Estado diante da precedente provocação jurisdicional aplicado através das ações penais que se subdividem em públicas e privadas conforme as disposições contidas em lei, ressaltando as excepcionalidades dos casos que dependem da condição da vítima para a imputação da sanção penal.

Logo após, apresentamos os efeitos da Lei Maria da Penha que incidiu diretamente nos crimes de lesão corporal leve e culposa concluindo que se procede independentemente da vontade da vítima restando na incondicionalidade da ação conforme entendimento pacificado pelo Superior Tribunal de Justiça e Supremo Tribunal Feral que fundamentaram pela incidência do artigo 41 da Lei 11.340/2006 afastando as disposições da Lei 9.099/95.

Quanto as contravenções de vias de fato, apesar da doutrina ponderar pela condicionalidade da ação diante da obviedade do fato em espécie, a suprema corte já se manifestou pela incondicionalidade da ação.

Sendo assim, os tratados internacionais, a legislação especial que trata sobre violência doméstica e familiar e a jurisprudência majoritária e pacificada pela Suprema Corte que os crimes de lesão corporal e vias de fato é de ação penal incondicionada, afastando o direito da vítima em renunciar a representação e autorizando o Estado na atribuição de medidas de rigor dentro do ambiente doméstico quando provocado.

Pois é imprescindível o tratamento rigoroso quando tratamos sobre crimes cometidos no ambiente doméstico, devido a observância das circunstâncias que antecedem os fatos e na dificuldade em descobrir a ocorrência do crime consistir na vontade da vítima. 
Logo, conclui-se que fez bem o atual entendimento da Suprema Corte em tratar crimes de lesão corporal e contravenções penais de vias de fato como de natureza incondicionada, tendo em vista, a seriedade do crime não consistir apenas na agressão estipulada no direito material e sim a relevante importância da coragem da vítima em estar disposta em abandonar suas raízes econômicas e afetivas da família e procurar proteção Estatal sob pleito de renúncia.

\section{REFERÊNCIAS}

BIANCHINI, A. Lei Maria da penha: lei n. 11.340/2006: Aspectos assistenciais, protetivos e criminais da violência de gênero, 3. ed. São Paulo: Saraiva, 2016.

CAPEZ, F. Curso de processo penal, 20.ed. São Paulo: Saraiva, 2013.

CUNHA,R. Manual de Direito Penal: Parte especial, 7.ed. Salvador: Jus Podivm, 2015.

Manual de Direito Penal: Parte geral, 3.ed. Salvador: Jus Podivm, 2015.

CUNHA, R: PINTO, R. Legislação criminal especial, 2. ed. São Paulo: Revista dos tribunais, 2010.

JESUS, D. Violência contra a mulher: Aspectos criminais da lei n.11.340/2006, 2. ed. São Paulo: Saraiva, 2015.

MARCÃO, R. Curso de processo penal, São Paulo: Saraiva, 2014.

MOUGENOT, E. Curso de processo penal, 11. ed. São Paulo: Saraiva, 2016.

NUCCI, G. Leis penais e processuais penais comentadas, 9. ed. Rio de Janeiro: Forense, 2015.

Código penal comentado, 15. ed. Rio de Janeiro: Forense, 2015.

PRADO, R: CARVALHO, É: CARVALHO, G. Curso de direito penal brasileiro: Parte geral e parte especial, 14.ed. São Paulo: Revista dos Tribunais, 2015.

PACELLI, E. Curso de Processo Penal, 21.ed. São Paulo: Atlas, 2017

BRASIL. Supremo Tribunal Federal. Ação declaratória de inconstitucionalidade 4.424. Requerente: Procurador Geral da República. Vistos, relatados e discutidos estes autos, acordam os Ministros do Supremo Tribunal Federal em julgar procedente a ação direta para, dando interpretação conforme aos artigos 12, inciso I, e 16, ambos da Lei no 11.340/2006, assentar a natureza incondicionada da ação penal em caso de crime de lesão corporal, pouco importando a extensão desta, praticado contra a mulher no ambiente doméstico, nos termos do voto do relator e por maioria, em sessão presidida pelo Ministro Cezar Peluso, na conformidade da ata do julgamento e das respectivas notas taquigráficas. 09.02.2012. Relator: Min. Marco Aurélio. Disponível em: http://redir.stf.jus.br/paginadorpub/paginador.jsp?docTP=TP\&doclD=6393143. Acesso em: 09. jun. 2017. 